\title{
In sweet harmony or in bitter discord? How cultural values and stakeholder requirements shape and users read an urban computing technology
}

\author{
Leena Ventä-Olkkonen \\ Netta Iivari \\ Arto Lanamäki
}

\author{
Human Computer Interaction and Human-Centered Development (INTERACT), Faculty of \\ Information Technology and Electrical Engineering (ITEE), University of Oulu \\ PL 8000, FI-90014 Oulun yliopisto, Finland \\ netta.iivari@oulu.fi \\ arto.lanamäki@oulu.fi \\ Corresponding author: \\ Leena Ventä-Olkkonen \\ leena.venta-olkkonen@oulu.fi \\ Mobile: +358504620384
}

\begin{abstract}
Culture is, in many ways, implicated in and shapes technology design and use. Inspired by Stuart Hall's conception of encoding/decoding, we maintain that technological artefacts reflect the cultural values of their creators, while users, in their encounters with the technological artefacts, may decode those artefacts in various ways that are shaped by the users' cultural values. In this article, we apply this lens to study a decade-long urban computing project that took place in the wild. We focus on the project's development team and on how their cultural values shape technology design. We also acknowledge that such an urban computing project involves many other stakeholder groups that affect the course of events. In our analysis, we examine how these stakeholders shaped and interpreted the technology in question. Although the development project had a seemingly generic "for all" ethos, the various stakeholders pulled the focus in different directions. The trajectory of the project can be characterized as reacting to these competing influences - sometimes achieving fit, while other times resulting in conflicts. The contribution of this paper is a structured analysis and reflections on cultural issues in community technology design in the wild, with a focus on the role of the developers' cultural values and other stakeholders' technology-related requirements and interpretations. This study has implications for subsequent studies in the wild by framing them as fluid settings of a great variety of stakeholders with a multiplicity of values, requirements, and interpretations.
\end{abstract}

Keywords Cultural aspects $\cdot$ Urban computing $\cdot$ Cultural match $\cdot$ Cultural diversity $\cdot$ Cultural values $\cdot$ In the wild 


\section{Introduction}

A central goal of participatory and human-centric design approaches is that people whose lives will be affected by a technology should have a say in its development. Although few would argue against this goal, it is often difficult to translate everyone's viewpoints into technological doings. Urban computing development projects, such as those involved with public multipurpose displays (cf. Ojala et al. 2010), represent a particularly big challenge in this regard. The development of such technologies with public money for a public space in a democratic society necessitates the involvement of various organizations and individuals, not only those considered "designers" and "users."

In this article, we provide an analysis of a several years-long urban computing project, in which 18 public multipurpose display screens were deployed in the city of Oulu, Finland. This project was a joint initiative between the local university and the municipal government. The aims of the project were to enhance citizens' mundane lives, boost municipality-citizen communication, and provide a testbed for ubiquitous computing research "in the wild." However, the displays never became a big hit among local citizens. Many displays remained unused, while others collected clicks only during special events or periods. A display located in the entrance hall of the swimming center (see Fig. 1) was a positive exception, inviting constant use throughout the year: as many clicks as the other 17 displays combined.

In sum, the project achieved some success but also had clear shortcomings. We became interested in the trajectory leading to such an outcome and examined the project through various qualitative means. Our previous analyses of the data revealed various influences that shaped the project and its outcomes. Our previous papers identified inter-stakeholder conflicts that could help explain the failures and successes (Ventä-Olkkonen et al. 2016). In the present study, we dig deeper, using a new and perhaps surprising analytical lens: cultural values. The cultural lens guides to inquire the underlying, takenfor-granted aspects that shape our daily lives and offers insights behind the scenes. Urban computing projects have lacked such analyses. This article, thus, examines the cultural values that shaped the project and its outcomes, that is, urban computing technology. Our research questions are as follows: 1) What kind of cultural values shaped the development and its outcomes? 2) How did other stakeholders interpret and influence the technology development process and its outcomes? We particularly inquire whether the interpretations and requirements of the other stakeholders aligned or conflicted with the values that drove the development team.

Cultural analyses of technology design (e.g., Flanagan et al. 2005; Iivari 2006; Sabiescu et al. 2014; Winschiers-Theophilus et al. 2015) and use (e.g., Lindtner et al. 2012; Martinviita et al. 2015; Ogan et al. 2012) have become prevalent. Regarding technology design, previous researchers addressed the challenges and practices of cross-cultural user interface design (e.g., Marcus and Gould 2000) and participatory design (e.g., Sabiescu et al. 2014; Winschiers-Theophilus et al. 2015). However, cultural analyses of long-term multi-stakeholder technology design projects are rare. Some studies addressing these projects came close, for example, by addressing the intricacies and challenges of collaboration (e.g., Halkola et al. 2015; Sabiescu et al. 2014; Ståhlbröst et al. 2015; Winschiers-Theophilus et al. 2015 ) that have also been studied in ubiquitous computing and public display projects (Cheverst et al. 2012; Clinch et al. 2011; Dalsgaard and Halskov 2010; Friday et al. 2012; Memarovic 2015; Memarovic et al. 2013; Suopajärvi et al. 2012; Taylor et al. 2013; Taylor and Cheverst 2009; Taylor and Cheverst 2010; Ylipulli and Suopajärvi 2013). Some studies addressed cultural aspects of developing country or community technology design contexts, within which it has been shown that local cultural aspects must be taken seriously by the designers who represent another culture (Sabiescu et al. 2014; Winschiers-Theophilus et al. 2015). These studies indicate that the way designers encode technology is shaped by their culture, among other things, and similarly, the users' cultural context shapes the way they decode technology. Thus, design and use are shaped by cultural influences, which can easily lead to various kinds of incompatibilities. 
In this article, we examine the shared, co-constructed cultural values that shape an urban computing project and its outcomes. Therefore, we focus on the developer perspective that we also contrast with the perspectives of other stakeholders. For the study, we view culture through a value lens. The view of culture as values is rooted in a long history in sociology (Weber 1958) and anthropology (Kroeber and Kluckhohn 1952). We adopt a widely accepted, very general definition from Giorgi et al. (2015) that values are "what we prefer, hold dear, or desire" and examine how such values are implicated in an urban computing project and technology. Thus far, the research community has remained silent about the phenomenon of cultural shaping of urban computing projects and outcomes with a multitude of stakeholders with their own values and interests. Overall, the contribution of this paper is a structured analysis and reflections on cultural issues in community technology design in the wild.

The structure of the paper is as follows. In the following section, we introduce the cultural lens utilized in this article. In section 3, we describe the research methods and the data collection and analysis procedures. In section 4, we present the empirical findings, while in section 5, we discuss their implications. Finally, in section 6, we summarize the main findings and their implications for research and practice, as well as identify limitations of the study and paths for future work.

\section{Figure 1A and 1B here side by side}

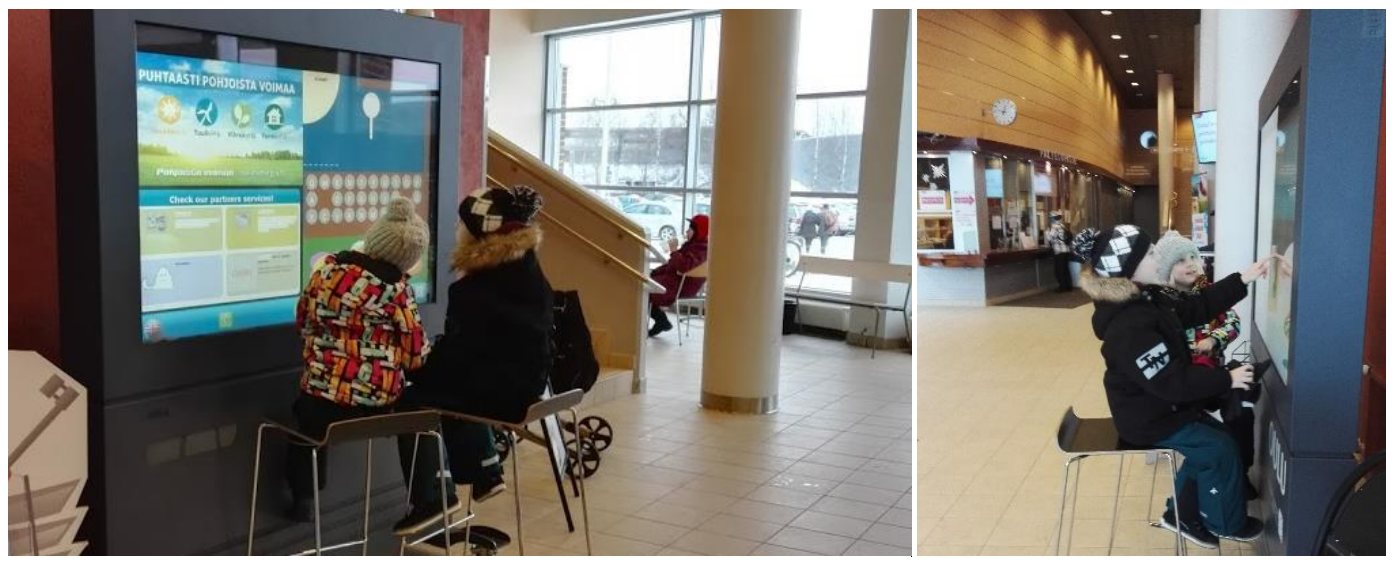

\section{Cultural lens}

Fig. 1 A public display in use at the swimming center

The examination of culture originates from the tradition of cultural anthropology; however, even within this discipline, there is a lot of confusion and controversy about the definition of culture (Kroeber and Kluckhohn 1952). The definitions highlight culture as historical, as including ideas, patterns, and values, as distinctive, as learned, as being based on symbols, and as an abstraction from behavior and products of behavior. The definitions have traditionally included some, if not all, of the following: specific language, values, norms, attitudes, customs, beliefs, knowledge, art, morals, behavioral patterns, habits, ideas, and symbols (Keesing 1998; Kroeber and Kluckhohn 1952). Especially cognitive, symbolic, and structural schools in anthropology have had a central position within the past few decades (Allaire and Firsírotu 1984). Geertz (1973), a famous anthropologist representing the symbolic school, states that "man is an animal suspended in webs of significance he himself has spun, I take culture to be those webs, and the analysis of it to be therefore not an experimental science in search of law but an interpretive one in search of meaning" (p. 5). The symbolic school views culture as a system of shared symbols or meanings, with researchers seeking out local interpretations in order to reveal cultural meanings from the native's point of view (Geertz 1973).

Whilst traditionally anthropologists studied cultures different from their own, often in exotic locations and within indigenous communities, culture is also a prominent topic in organizational studies, within 
which the anthropological notions of culture have offered widely used points of departure (Allaire and Firsírotu 1984; Smircich 1983). Czarniawska-Joerges (1992), however, warns that studies on organizational culture can nearly always be connected to cultural anthropology, but in many cases, the label is used only as a metaphor, not as an approach: Consultants have used culture as an attractive metaphor; however, this has had nothing to do with analytic purposes but instead with control. In the organizational context, then again, scholars long ago acknowledged that organizations are actually multicultural: Various kinds of subcultures and occupational and professional cultures must be acknowledged within (e.g., Czarniawska-Joerges 1992; van Maanen and Barley 1984). As an addition to this cultural diversity, studies have acknowledged that projects may develop a culture of their own - which may be shaped by the culture of the organization(s) involved, as well as by various kinds of subcultures and occupational or professional cultures (e.g., Ajmal and Koskinen 2008; Van Marrewijk 2007). Moreover, within and outside organizational boundaries, various kinds of (online, offline) communities of practice (Brown et al. 1989; Lave and Wenger 1992; Wenger 1998) have been identified that have distinct cultural characteristics (e.g., Iivari 2005).

In the context of technology design and use, studies on culture have aroused increasing interest. These studies examined the influence on or the significance of culture in relation to technology design and use. The studies derived their inspiration from various sources, including cultural anthropology and organizational studies, and thus, they rely on very divergent notions of culture (Czarniawska-Joerges 1992; Iivari 2006, 2010). The studies can be categorized as comparative, clinical, or interpretive (Iivari 2006, 2010), of which only the interpretive approach relies on the tradition of cultural anthropology. Within the comparative approach, culture is approached as an independent, explanatory variable that can be measured and compared. Researchers seek cause-and-effect relationships (Iivari 2006, 2010; Ouchi and Wilkins 1985). The comparative approach has received considerable interest in studies on technology design and use, and studies have identified compatible types of culture for different kinds of technologies or compatible technology implementation strategies for different types of culture (Iivari 2006, 2010). The clinical approach examines culture as a dependent variable for which some treatment is experimented with and its effects examined (Iivari 2006, 2010). This approach relies on the assumption that cultures can be intentionally designed, managed, and changed (Czarniawska-Joerges 1992; Gallivan and Srite, 2005; livari 2006, 2010; Schein 1985). This approach has been popular in studies on technology design and use: Studies have identified ideal cultures for different kinds of technology-related endeavors and guidelines on how to treat culture to achieve the desired end (Iivari 2006, 2010). Both approaches can be criticized as relying on very naïve notions of culture: The comparative approach views culture as a variable, and the clinical approach even as a designable, manipulable dependent variable; one can criticize the instrumental, utilitarian aspect that contradicts the notion of culture developed within cultural anthropology (Iivari 2006, 2010).

In contrast, the interpretive approach aligns with the tradition of cultural anthropology and views cultures as socially produced and reproduced, in the analysis of which the focus should be on meaning-making from the native's point of view (Czarniawska-Joerges 1992; Iivari 2006, 2010). These culture studies in the context of technology design or use investigated the interpretations and meanings attached to technologies, as well as the reciprocal relationship between culture and technology, showing that new forms of cultural knowledge and changes in the cultural context may also emerge, but without intentional effort or managerial design (Iivari 2006, 2010). However, also this approach has received criticism during the past few years. Critics maintain that culture should not be viewed as a static, shared pattern or whole, but instead as plural, fragmented, emergent and continuously open to interpretation. If cultures are seen as systems of shared meanings, one must acknowledge that these meanings are continuously negotiated and struggled over (Clifford and Marcus 1986; Keesing and Strathern 1994; Ortner 1999). People continuously spin the fragile webs of meanings, and the focus should be on meaning-making, not on the system (Ortner 1999). The literature maintains that the concept of cultural should be preferred instead of the concept of culture, 
as this highlights the fragmented, emergent nature of culture, as well as avoids essentializing and reifying it (Clifford and Marcus 1986; Keesing and Strathern 1994; Ortner 1999).

This study aligns with this view and empirically examines cultural aspects intertwined with technology design. The focus is on the cultural values that drive technology design. Values have commonly been used to characterize culture (e.g., Keesing 1998; Kroeber and Kluckhohn 1952), including organizational culture (Schein 1985). Values, in general, refer to what is considered important, good, and right in life (cf., e.g., Iversen et al. 2010; Miller et al. 2007; Schein 1985) among the members of a culture, such as within a community, organization, or project. Such values are shared among the members of the culture and drive or underlie their behavior, and therefore have implications for technology design and use. In this article, such values are, however, not viewed as a static, shared, fixed set that can be comprehensively captured but instead as a plural and emergent constellation that is continuously open to interpretation and negotiation (cf. Clifford and Marcus 1986; Keesing and Strathern 1994; Ortner 1999). Although in this study we do not consider that the values form a static, collective entity, there must be some sort of consensus or sharing among the members of the culture before the values can be labeled cultural values.

When examining cultural values in the context of technology design and use, we utilize the encoding/decoding lens from communication studies introduced by Stuart Hall (1980). In the context of technology design, we assume that technology always contains a message encoded by designers during the production process. This encoding is always shaped by various structures, practices, networks, relations, ideologies, assumptions, and infrastructures, including the development team's cultural values. The encoded technology must be decoded by users when they encounter and appropriate that technology. Their decoding is also shaped by various structures, practices, networks, relations, ideologies, assumptions, infrastructures, and values. Although designers have always encoded a preferred reading in the technology (Grint and Woolgar 1997; Hall 1980), users can, in addition to adopting it, decode the message in negotiated or even opposing ways (Hall 1980). We examine an urban computing project and technology, about which we show that 'designers' and 'users' include various kinds of people with differing interests and requirements for the project and its outcome. This diversity complicates the encoding/decoding processes further.

In addition to examining cultural values that shape technology design, in this study we acknowledge conflicts that may emerge when many stakeholders enter the project and engage with the displays. In the literature on culture and technology, conflict and compatibility have been recurrent themes, with an assumption that compatibility or fit is needed to succeed (Gallivan and Srite 2005; Iivari 2006, 2010). Comparative and clinical culture studies have identified compatible types of culture that fit particular technologies, compatible technologies that fit particular types of culture or compatible implementation strategies that enable fitting technologies with particular types of culture (Iivari and Iivari 2011; Iivari 2006, 2010). Mutually reinforcing and emergent views, furthermore, can be found in culture studies that represent the interpretive approach. These studies emphasize that the cultural context may reinforce certain aspects of technology, while deeming other aspects less important, and that technology may also modify the cultural context in a complex, emergent, reciprocal relationship (Gallivan and Srite 2006; Iivari and Iivari 2011; Iivari 2006, 2010). In this article, the cultural values that shape technology design are examined and contrasted with the perspectives of a number of stakeholder groups, showing that occasionally compatibility emerged or was achieved (i.e., the recipients adopted the preferred reading inscribed in technology), while other times conflicts surfaced instead (i.e., the recipients read the message in a negotiated or even opposing way). Such matches and clashes were identifiable among a multitude of designers and users involved in this in the wild urban computing project, and they emerged during the encoding and decoding processes. During encoding of the message, differing requirements were attached to the technology in question, while during decoding it, various interpretations emerged. The developers' cultural values played a role in shaping the message, while other stakeholder groups also had a say. Some users adopted the preferred 
reading of the technology; thus, compatibility was achieved. Other users interpreted the technology in negotiated or even opposing ways; therefore, conflicts surfaced.

\section{Research design}

This section presents the case and the methods and procedures for collecting and analyzing the data.

\subsection{Open UBI Oulu case}

This article focuses on the ubiquitous urban computing infrastructure (Open UBI Oulu) consisting of 18 interactive public screens located around the city of Oulu in northern Finland. The displays are located in outdoor (pedestrian street, marketplace) and indoor positions (library, university, sports centers). The UBI displays are large 57" screens with full high-definition liquid crystal display (HD LCD) panels. The displays are equipped with a touch screen foil, a control computer, a local hard drive, two cameras, a near field communication (NCF) and Radio-frequency identification (RFID) readers, and a loudspeaker. The content of the displays consists of various entertainment and informative services, such as news, weather, bus schedules, local service information, and entertainment, such as games and art installations but also commercial advertisements. The content has changed over time: Some applications have been removed while new ones have been launched. The infrastructure was launched in 2009, and since then, many studies about the Open UBI Oulu case have been published (Kukka et al. 2014; Ojala et al. 2010; Suopajärvi et al. 2012; Ylipulli et al. 2014a, 2014b; Ylipulli and Suopajärvi 2013). However, these studies did not provide a cultural analysis of the project and its associated conflicts. This is how the present study contributes to the literature.

The display project has not been a success from every perspective. The most visible drawback is the lack of multipurpose display use, as well as the general attitude of citizens toward the displays. The use rate of the public displays has slowly decreased over the years (c.f. Ylipulli et al. 2014b), and negative comments have been vibrant on (social) media. From the perspective of the project, we consider the main stakeholder groups to be developers and users. Qualitative studies on both stakeholder groups have been carried out. We interviewed the development team to understand the progress of the project and the factors contributing to the current state of the display network. Additionally, we carried out an ethnographic field study and theme interviews with the display users. One display stands out with a higher usage rate than the other displays together. Frequent usage of this display, located at the entrance hall of a swimming pool center, indicates existing user practices and communities in this location. For this reason, we decided to conduct the field study on this particular display. While recruiting participants for the study, we identified also users of another display located in a school lobby. These users also used the swimming center display at some point. In addition to these two main stakeholder groups, we study the perspectives of city inhabitants through social media, as well as the municipality through theme interviews. Finally, we take an indirect look at the perspective of advertisers through theme interviews of the advertisement sellers, who were members of the development team.

\subsection{Methods and material}

The research data that informs this article was collected from five sources: developers, city representatives, advertisement sellers, display users, and citizens. Next, we introduce each data set in more detail. The data in this article is summarized in Table 1.

The first part of the material consists of eight in-depth interviews conducted with people who had been employed in the project. These individuals worked for the university. They had distinct roles in different stages of the project, involving tasks such as management, software development, maintenance, and research. Two interviewed members of the project team concentrated on selling 
broadcast time on the display surface to advertising companies. These team members did not participate in designing or implementing the services but interacted closely with the advertisers, and thus had comprehensive knowledge of the advertisement requirements related to the technology. We used this interview material to investigate the advertisers' technology-related requirements.

The interview method was based on semi-structured interviewing (Myers and Newman 2007), which was supported by the use of a timeline. Timeline interviews have a tradition in the humanities and nursing (Adriansen 2012; Sheridan et al. 2011; Tolvanen and Jylhä 2005). The interviewee marks important events on a trajectory while the interview is conducted. Although this approach is rarely used in technology studies, we have found it useful in reconstructing projects after the fact. During the interview, the participants were asked to draw a timeline of the project from their own perspective. They were asked to mark the highlights of the project and report personal events related to the project. The timeline was used to outline the process of the project and as a memory support for the informant and the researchers during the interviews. Each interview lasted for 56-156 minutes. Most participants were interviewed once, but due to scheduling issues, one participant was interviewed twice. Interviews were audio-recorded and transcribed, and the hand-drawn timelines were photographed. Two researchers conducted all the interviews.

In addition, we interviewed three representatives of the municipality, who were involved in the design phase and still utilized the display network to promote events. One of the two interviews was a pair interview, in which two youth and culture center employees (cultural producers) were interviewed together. These interviews were semi-structured and lasted approximately 40 minutes each. Two researchers conducted these interviews.

To gain insights into the users, we utilized material collected from 39 display users. This material was collected through field interviews at the swimming pool entrance hall where the most frequently used UBI display is located. Most of the frequent display users are children in this location, and most of the interviewees were 3- to 17-year-old children and teenagers. The youngest users were interviewed with their parents. For research ethical reasons, parental permission was required for all under-aged interviewees. The interviews were structured and based on a pattern of 23 questions about display use habits and attitudes toward them. The field interviews lasted approximately 5-10 minutes and were audio-recorded and transcribed. To deepen our understanding of the users, we also conducted thematic interviews with nine display users. These users were 9- to 16-year-old children and adolescents. All of the interviewees had used the swimming center display, but five were more familiar with and used the display located in the lobby of their comprehensive school more frequently. The interviews were semi-structured and loosely followed a question pattern designed to shed light on technology appropriation. The interviews lasted approximately 30 minutes. Two of the interviews were pair interviews. All the interviews were audio recorded. One researcher conducted all of these interviews. The thematic interviews were selectively transcribed.

The fourth part of the research data consists of 216 discussion forum and comment section posts from the online version of a local newspaper (Kaleva). Most of the posts are comments on journalists' articles about the displays. However, some comments threads were initiated by readers.

Table 1 Data sources, informants, methods, and rationale

\begin{tabular}{llll}
\hline Data & Informants & Methods & Rationale \\
\hline $\begin{array}{l}\text { Display developer } \\
\text { interviews } \\
\text { (about 1-2 hours each) }\end{array}$ & $\begin{array}{l}\text { 6 project employees from } \\
\text { the university }\end{array}$ & $\begin{array}{l}\text { Semi-structured timeline } \\
\text { interviews; } \\
\text { data-driven analysis } \\
\text { inspired by value lens }\end{array}$ & $\begin{array}{l}\text { To understand the shared } \\
\text { cultural values of the project } \\
\text { team and get insights into } \\
\text { other stakeholders' } \\
\text { requirements }\end{array}$ \\
\hline $\begin{array}{l}\text { Advertisement seller } \\
\begin{array}{l}\text { interviews } \\
\text { (about 1 hour each) }\end{array}\end{array}$ & $\begin{array}{l}\text { 2 persons work on the } \\
\text { project in advertising sales }\end{array}$ & $\begin{array}{l}\text { Semi-structured timeline } \\
\text { interviews; data-driven } \\
\text { analysis inspired by value } \\
\text { lens }\end{array}$ & $\begin{array}{l}\text { To understand the advertisers' } \\
\text { shared requirements and the } \\
\text { project team's cultural values }\end{array}$ \\
\hline
\end{tabular}




\begin{tabular}{|c|c|c|c|}
\hline $\begin{array}{l}\text { City representative } \\
\text { interviews } \\
\text { (about } 40 \text { min each) }\end{array}$ & $\begin{array}{l}3 \text { city representatives: } \\
1 \text { works at the city's youth } \\
\text { department, } \\
2 \text { work at a youth and } \\
\text { culture center }\end{array}$ & $\begin{array}{l}\text { Semi-structured } \\
\text { interviews; } \\
\text { data-driven analysis } \\
\text { inspired by value lens }\end{array}$ & $\begin{array}{l}\text { To get insights into the } \\
\text { municipality's technology } \\
\text { requirements }\end{array}$ \\
\hline $\begin{array}{l}\text { Field user interviews } \\
\text { (about } 5 \text { min each) }\end{array}$ & $\begin{array}{l}36 \text { display users (mainly } \\
\text { children) }\end{array}$ & $\begin{array}{l}\text { Structured field interviews; } \\
\text { data-driven analysis } \\
\text { inspired by value lens }\end{array}$ & $\begin{array}{l}\text { To understand the users' } \\
\text { shared technology-related } \\
\text { interpretations and } \\
\text { requirements }\end{array}$ \\
\hline $\begin{array}{l}\text { Thematic user } \\
\text { interviews } \\
\text { (about 30-50 min each) }\end{array}$ & $\begin{array}{l}9 \text { display users ( } 9 \text { to } 15 \\
\text { years old), two were } \\
\text { couple interviews }\end{array}$ & $\begin{array}{l}\text { Semi-structured } \\
\text { interviews; } \\
\text { data-driven analysis } \\
\text { inspired by value lens }\end{array}$ & $\begin{array}{l}\text { To understand the users' } \\
\text { shared technology-related } \\
\text { interpretations and } \\
\text { requirements }\end{array}$ \\
\hline Social media data & $\begin{array}{l}\text { Discussion forum and } \\
\text { comment section writers }\end{array}$ & $\begin{array}{l}\text { Data-driven analysis } \\
\text { inspired by value lens }\end{array}$ & $\begin{array}{l}\text { To understand the users' and } \\
\text { citizens' shared technology- } \\
\text { related interpretations and } \\
\text { requirements }\end{array}$ \\
\hline
\end{tabular}

\subsection{Data analysis}

The nature of the analysis was data driven, supported by the Hall-inspired cultural lens as a sensitizing device. We first transcribed the audio-recorded interview material. Then we read the transcriptions. We identified the issues that each stakeholder group considered important.

We sketched the first draft of cultural value categorization based on the developer perspective; we identified findings for what the developers preferred, held dear, or desired (cf. Giorgi et al. 2015) for the project and its outcomes. Additionally, we categorized the technology requirements of the advertisers and the municipality. As the final step of the analysis, we identified the users' and inhabitants' interpretations of the project and its outcomes. We acknowledged that the research data did not enable us to study the cultural values of these other stakeholder groups.

As the most profound research data was collected from developers, the analysis centers on their cultural values. We studied users' interpretations through the thematic and field interviews. The users' perspective is also addressed during the developer interviews. The inhabitants' perspective was investigated mainly through the social media data of the local newspaper. The municipality perspective was included mainly in the developer interviews, in which the developers describe how the municipality was involved in different stages of the project. In addition, we included interview data from three city representatives, who were involved in the design process. The advertisers' perspective was identified from the advertisement sellers' interviews.

After the initial value, requirement, and interpretation categorizations, quotations from the categories were highlighted from the text, and the categorizations were iterated. In the next phase, the categorizations and the corresponding quotes were read through and discussed by a group of three researchers and iterated further. This phase led to identification of the conflicts and compatibilities associated with the developers' cultural values. When we went through the material, we also realized that although some of the identified values were stable and similar and drove the project from the very beginning, others changed and evolved over time. Finally, the users' interpretations were categorized into three groups: preferred reading, negotiated reading, and oppositional reading. To categorize the findings, we used Hall's (1980) decoding and encoding framework (see Fig. 2).

\section{Figure 2 here}

Fig. 2 Encoding and decoding process for the public displays 


\section{Encoding the artefact: cultural values of the developer team within the urban computing project}

In this section, we describe the cultural values of the developer team that drove the urban computing project. Technology is always encoded with the designer's cultural values. In the UBI Oulu case, the developers' values are clearly visible, shaping the project and its outcomes. By culture, we mean the shared (although evolving) culture that emerged within the project, which likely has been shaped by various kinds of organizational, occupational, professional, and community of practice cultures to which the project members belong and have experience of.

\subsection{World-class research}

In the UBI Oulu case, the leading ethos of the developer team was the importance of the research. The value of high-quality research links to all the other shared cultural values of the developers identified in the project. In the UBI Oulu case, the developers are at the same time researchers. Interestingly, however, although first the developers were researchers working at the university, especially in the beginning of the project the set-up was not actually this. The developers describe the atmosphere of the beginning as a "start-up spirit." The developers were working together for a common goal. Work hours were not counted, and research was not thought about. The aim was to get a working public display network system ready in time. In the beginning, the developer team was inexperienced in research. Except for the team leader, there were no post-doctoral-level researchers in the group, and thus, the developers were not able to think about their work from the research perspective. The developers were creating innovations, but they did not know how to write research papers about the innovations. In the quotation 4/1, a developer describes the spirit of the initial stages. However, the researcher identity and research values became stronger during the project. The developers started to see the project more as a research project. The displays presented research demonstrations and were supposed to function as research enablers with changing content, not as ready-made commercial products (quotes 4/2 and 4/3).

One strategy for reaching the standard of world-class research was conducting studies in the actual world rather than in a laboratory. Therefore, doing research in in the wild was a central point of the project. The original idea was to be the first to establish a ubiquitous computing laboratory in a realworld environment. Thus far, ubiquitous computing research had been "toy research," as a developer described it, and had not provided real knowledge of how these ubiquitous computing experiments really worked. Realizing the true importance of in-the-wild research was seen as the main contribution of the UBI display project. The quotation $4 / 4$ from the lead developer describes how this was shown in the project.

\begin{tabular}{|c|c|}
\hline \# & Quote \\
\hline $4 / 1$ & $\begin{array}{l}\text { We didn't have any post docs. We didn't have anybody who could have mastered research work. So, we worked } \\
\text { hard and did all sorts of innovative things with a kind of a start-up spirit. But we didn't have anybody who } \\
\text { could have said, "Write a paper about this and that, and do it like this." So, the research was very much hit- } \\
\text { or-miss. (Developer \#3) }\end{array}$ \\
\hline $4 / 2$ & $\begin{array}{l}\text { But the first software version was, well, the first version. If we had had more hands and more time, we could } \\
\text { have found and repaired most of the bugs in the lab, which we found the hard way during that summer. But } \\
\text { we were not making a commercial product but a sort of research prototype. (Developer \#3) }\end{array}$ \\
\hline $4 / 3$ & $\begin{array}{l}\text { It has always been my view that the UBI displays are research enablers. Meaning, that we didn't have one } \\
\text { specific vision. Instead, we make displays that are exactly like this with these services. (Developer \#1) }\end{array}$ \\
\hline $4 / 4$ & $\begin{array}{l}\text { UbiComp studies are a sort of toy studies, meaning that nothing is made properly. I turned the vision so that } \\
\text { we have made an investment in a ubiquitous technology laboratory that is in real use. I was especially } \\
\text { interested in the context of a city-I can give you a concrete example of how the lab, or a sort of controlled } \\
\text { (environment), is a bad predictor or foreseer. We had this Wordster game, where you were supposed to find } \\
\text { as many words as possible from a grid of words within a time limit. And we tested two circles first on campus, } \\
\text { in a controlled situation. All the people who tested it, we just took passers-by. It was multiplayer; it had to be }\end{array}$ \\
\hline
\end{tabular}


played with a phone. Everybody had their own user interface, a private user interface. And then the public game board was visible there [in the UBI display]. One had to scan the QR code so that you were able to pair the smartphone with the game. About 90 percent said that it worked very well. So, we put it on all of the UBI displays and then spied on, or sorry, observed, people when they used the UBI displays. And only a very small portion of the first 1600 multi-play users were able to do it. (Developer \#1)

\subsection{Researchers' freedom}

As the researcher identity became stronger, researchers started to manifest as well strong views about the freedom of the researcher. The developer-researchers did not want to be "code slaves" or just "engineers" anymore. They wanted to do their own research and promote their own academic careers. The researchers wanted to choose what to study and how. Non-academic maintenance work was seen as a required thing to do, which took time from real research work. Distributing the required maintenance work caused tension among the team members.

\begin{tabular}{cl}
\hline$\# \quad$ Quote \\
\hline $\mathbf{4 / 5}$ & I think it was about 2011 when people started to get fed up with the maintenance work. -So people started to \\
& resist the maintenance work, which was a relatively routine job. It takes the whole day to go somewhere to fix \\
& a screen. People who are doing their PhDs are not interested in doing this several times a year. Although it's \\
& not a big thing actually, it's sort of extra work compared to the job that you had imagined, promised, and were \\
& ready to do. (Developer \#5)
\end{tabular}

\subsection{Cutting-edge technology}

The research on the project concentrated mainly on technological innovations. One of the values from the beginning of the project was new technologies and scientific innovations. To make better research contributions, the developers did not want to settle with off-the-shelf solutions, either hardware or software. The display hardware had to be specially equipped and robust. Ordinary digital sign hardware could not be counted on as the developers had customized the displays (Quote 4/6). In software development, innovations were searched from, for example, distributed user interfaces and solutions for adaptable, context-aware advertising. The value of new cutting-edge technologies and scientific innovations was clearly shared among the developers, and everybody stood behind it. This value remained important until the end of the project, although other types of research contributions were recognized.

\begin{tabular}{cl}
\hline$\#$ & Quote \\
\hline $\mathbf{4 / 6}$ & Well, we wanted to get high-powered hardware. The basic hardware that, by default, is in average digital \\
& signs is not very powerful ... in other words, we upgraded pretty much the basic composition. And the supplier \\
& had to tailor it a lot. There was the sensor, RFID reader, camera, all sorts of additional things, loudspeakers, \\
& and these kinds of things. (Developer \#2)
\end{tabular}

\subsection{Power in numbers}

Another value of the developer team seemed to be trust in the "power in numbers." This is related to respecting quantifiable data and statistical research, as well as aiming at a larger number of services and displays, and larger screens (quote 4/7). The mindset reflects the way data was collected from the displays. It was important to be able to measure and use statistics with the data. Quantitative research methods were valued as the right way to produce scientific knowledge. If qualitative data was collected, it was used to support and illustrate the quantitative findings. Qualitative data was collected through writing competitions and user studies, but these findings did not seem to be valued, and the developers did not utilize these findings when they developed the display applications (quote 4/8). However, when anthropologists joined the team and conducted qualitative research, the mindset of the original developers changed to appreciate qualitative research. 


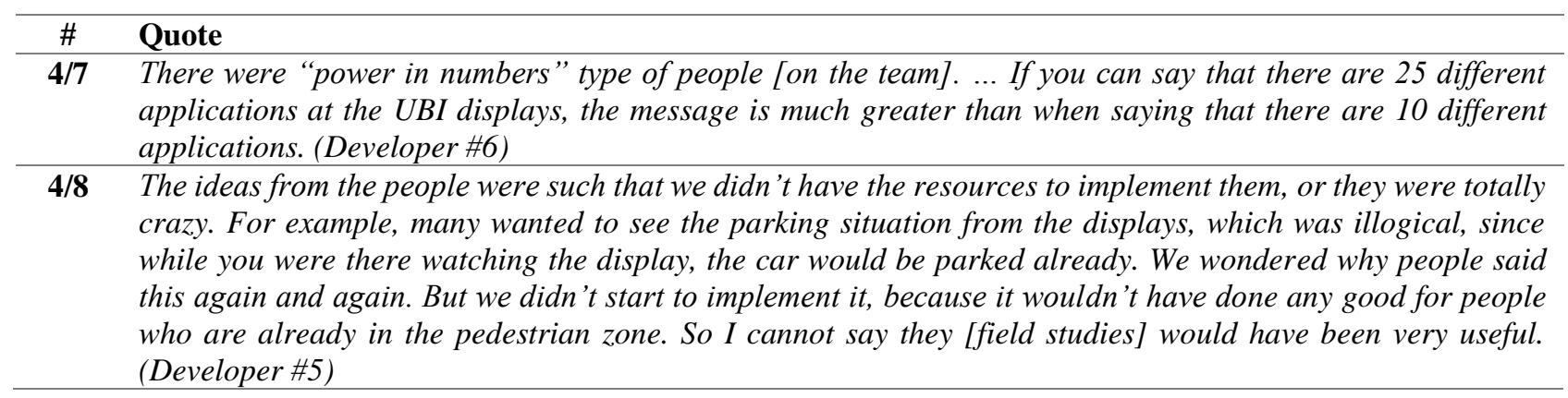

\subsection{Recognition}

Gaining recognition is another value associated with research. It was important to gain global recognition in the international academic world, as well as gain local attention for the project and the displays. Especially in the beginning of the project, the team spirit was enthusiastic, and the aim was to do something big, visible, and significant together. For improving the project visibility internationally, a summer school tradition was created. The summer school track turned out to be a success and spread the word in the academic world. However, another event that attempted to gain global visibility for the project, the UBI Challenge, was discontinued after two years.

In addition to seeking recognition, the developer-researcher team was keen to gain positive local visibility for the project and the displays. The team envisioned how the displays would be attractive and stand out in the cityscape. Furthermore, attention was sought through stories published in local media and through, for instance, a writing competition that tried to engage inhabitants. Unfortunately, after the displays were launched, the attention in local media was not always positive. The negative stories might have influenced the subsequent public opinion.

\section{Encoding the artefact: technology requirements of advertisers and the municipality within the urban computing project}

In this section, we present the technology-related requirements of two central stakeholders: municipality representatives and advertisers. Both stakeholder groups were involved in the design process and participated in shaping the displays. In addition to the developer team's implicit values, these stakeholders' concrete technology-related requirements were encoded in the physical display network.

\subsection{The municipality's technology-related requirements}

The municipality had a big role in the implementation process of the public display network. The city's image was built on high technology; until recent years, the city's most visible symbol was Nokia. The public display research project fitted well with the city's image. The displays were installed in the city area, so the municipality had a say about the locations of the displays and their appearance. The municipality also had an impact on the display content. Later on, the city used the displays mainly to promote municipal events.

\subsubsection{Useful services}

The main purpose of a municipality can be considered that of serving its citizens. One motivation of the municipality for the involvement in the project-and thus the main requirement for the technology - was to provide useful services for citizens. The possibilities of the UBI displays were discussed in ideation sessions with different stakeholders. For example, ideas concerning marketing, distributing news and information, and collecting feedback were thought of (quote 5.1/2). Another 
idea, which was also implemented, was to replace the paper map signs around the city with electronic versions through the UBI displays. The UBI displays also tried to collect feedback from young inhabitants. However, these experiments remained short-term. Then again, not commercial non-profit services made it possible to place the displays in central locations in the city, where otherwise advertising was limited (quote 5.1/1).

\begin{tabular}{cl}
\hline$\#$ & Quote \\
\hline $\mathbf{5 . 1 / 1}$ & $\begin{array}{l}\text { So we got an exemption [to enter] the central area of the city, an area that had been protected from } \\
\text { advertising. We got the permit because of the interactive services that benefitted everyone. If we hadn't had } \\
\text { the third-party applications, we probably wouldn't have had access to the city center. (Developer \#2) }\end{array}$ \\
\hline $\mathbf{5 . 1 / 2}$ & $\begin{array}{l}\text { Our interest was to bring a new marketing medium for the cultural actors and cultural events of our city. } \\
\text { (Representative of the municipality \#1) }\end{array}$ \\
\hline
\end{tabular}

\subsubsection{Aesthetics}

Another important issue for the municipality was maintaining a coherent and aesthetic streetscape. This was relevant from the project's perspective: In the end, this issue strongly affected how the displays look now. The developers' original idea was to make the displays more prominent and enticing; however, the "city street view working group" determined the final size, color and appearance of the displays. The group's aim was to integrate the displays in the streetscape, so that they would not disturb the harmony of the colors or the design language (quote 5.1/3).

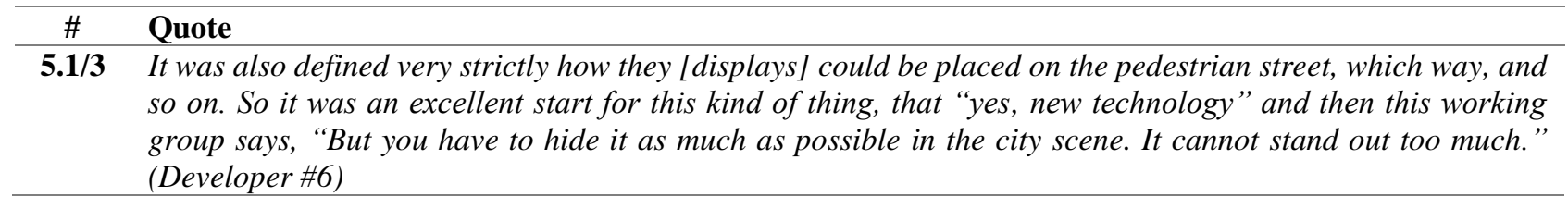

\subsection{Advertisers' technology-related requirements}

An advertisement channel was developed to cover the maintenance costs (electricity, the Internet, and cleaning) and to fulfill the public-private partnership terms that required maintenance of the set-up for eight years, even after the project funding period. Selling advertisement time was seen as the easiest way to cover the costs. The researchers had developed a full-screen advertisement mode next to the interactive mode. The advertisement mode was activated when nobody used the display or stood close to it. Therefore, the advertisers became an important stakeholder group involved in the project, and the developers had to consider carefully their technology-related requirements to keep the advertisers happy. Advertisers were funders in the sense that they provided money to keep the displays working. The advertisers' technology requirements (high visibility and reliability) differed from the developers' embedded values. The advertisers basically wanted just to have a good, riskless run for their money.

\subsubsection{High visibility}

The advertisers required visibility: They wanted as much visibility as possible for their advertisements (quote 5.2/1). The display consisted of two modes: an interactive mode with several interactive services and a full-screen advertisement mode with a list of rotating ads. The advertisements were also visible in the interactive mode, but they covered only about one third of the screen space. The interactive mode was more important for the developers. It was the place where the research applications were launched and where the usage statistics were collected. In the beginning, the modes switched through face detection. When a person came close enough to the display, the advertisement mode changed into the interactive mode. When the screen had not been touched for a while, the 
advertisement mode turned on automatically. This helped users notice the interactive services. However, the advertisers were not happy with this solution, as it reduced the visibility of their advertisements (quote 5.2/2). Therefore, face detection and the automatic shift to the interactive mode were changed into touch-based interaction so that the interactive mode was switched on through touching the display surface. This change caused a decrease in the use of the interactive services.

\begin{tabular}{|c|c|}
\hline \# & Quote \\
\hline $5.2 / 1$ & ... they [companies] want to buy an ad that is visible and that's it. (Developer \#3) \\
\hline $5.2 / 2$ & $\begin{array}{l}\text { Some local marketing leader took the heads of the customer company [the advertiser] to the pedestrian zone } \\
\text { display. - - And when they approached the display, the face detection worked and changed the advertisement } \\
\text { mode into the interactive mode. So they got upset and contacted us and said that when we went to look at the } \\
\text { advertisement it was small in the corner. What on earth is this? (Developer \#6) }\end{array}$ \\
\hline
\end{tabular}

\subsubsection{Reliability}

The visibility of the advertisements was the main concern for the advertisers. Innovativeness was not a high priority. What mattered to the advertisers was that they could rely on the fact that the displays would show the advertisements the companies had paid for. The advertisers seemed to prefer traditional advertisement channels. Even the digital mode seemed to be too much for some in the beginning of the project. In the following quotes, members of the developer team explain how the advertisers responded to the innovative advertising solutions the developers offered (quote 5.2/3).

Maintaining the complex software and hardware components was not easy. Especially in the beginning of the project, the displays crashed often. The displays malfunctioned due to different reasons. Sometimes it was the hardware, sometimes the software, and sometimes the Internet connection. It took a while for the developers to find and correct all the bugs and develop suitable practices for maintaining the displays. These interruptions in functionality affected the visibility of the advertisements. The interruptions angered some advertisers, and some withdrew their campaigns from the UBI displays (quote 5.2/4).

\begin{tabular}{cl}
\hline$\#$ & Quote \\
\hline $\mathbf{5 . 2 / 3}$ & $\begin{array}{l}\text { And these actors who buy advertisements in Oulu, they are not interested in being test rabbits in this sort of } \\
\text { new fancy adaptive context-aware advertisement system. (Developer \#3) }\end{array}$ \\
\hline $\mathbf{5 . 2 / 4}$ & $\begin{array}{l}\text { [Advertisers] said, "We only use the channels we are used to, and we are not going to try any completely new } \\
\text { media now." We had designed all sorts of camera detections and adaptive advertising. Then, all of the } \\
\text { [advertisers] just withdrew into a sulk and were like "we don't have the courage." (Developer \#6) }\end{array}$ \\
\hline
\end{tabular}

\section{Decoding the artefact: users' technology interpretations within the urban computing project}

After the developers and other stakeholders of the urban computing project had encoded their values and requirements in the technological artefact, the users got to see it, and the true test began in the wild. In this section, we describe the interpretations of the users and other city inhabitants when they confronted and interacted with the project outcomes. The interpretations were partially similar and partially different between the user groups (e.g., children versus adults). Some of the interpretations were positive (preferred reading), others were negative (opposite reading), and some were in between (negotiated meaning). The display users' interpretations and how well they were in line with the development team's encoded message determine whether the interactive displays would or would not be used, and thus, the success of the display project.

The findings for users, city inhabitants, and developers differ somewhat. Although the user community (mostly young people) values sociability and fun services, adult inhabitants mostly emphasize the importance of the utility and usability of the services. On social media, furthermore, the reliability and utility of the services are emphasized. We introduce the various technology interpretations of the public display user community, then we examine the users' and citizens' 
interpretations, and last we introduce those perspectives shared only by inhabitants. The first interpretations of the technology (offering entertainment and supporting sociability) show that users interpreted the technology in the way the developers intended; that is, the users adopted the preferred reading. However, the other interpretations show that this was not entirely the case: The users interpreted the technology in a negotiated (unusable/usable technology, useless/useful technology) or even opposing manner (threatening privacy, dirty technology, unreliable technology, disturbing technology).

\subsection{Users decoding technology within a preferred reading}

\subsubsection{Offering entertainment}

According to our observations, the users of the public displays, that is, those who actually use the displays somewhat frequently, are mostly children. In the interviews, these people say that the games are the most interesting and most frequently used content type. The more utile services are not mentioned or expected from the display with the exception of a map service, which is used for entertainment purposes, however. Most of the frequent users did not even know that other, more informative services and serious content are available. This is also indicated by the usage statistics that highlight that games were the most frequently used content. According to the users, they usually use the displays while waiting for something. The verb "wait" was mentioned in almost all of the field interviews and thematic interviews when the interviewees were asked about usage. Thus, the "time killing" aspect of the display use is highly valued by the young users and their parents. The games should be fun to play either alone or in groups. A bigger variety of games was also mentioned as a suggestion for improvement and a reason for using one's own phone instead of the display.

\begin{tabular}{cl}
\hline$\#$ & Quote \\
\hline 6.1/1 & Games are the nicest (Users 7,10 \&11 yrs) \\
\hline $\mathbf{6 . 1} / 2$ & Games are quite nice when you don't have anything else to do (User, 16 yrs) \\
\hline 6.1/3 & [Displays are good for] killing time, if you have to wait, and it [display] is free (Parent of a user, 8 yrs) \\
\hline $\mathbf{6 . 1 / 4}$ & Always when we went to the UBI display, we only played games with it. (User, 9 yrs) \\
\hline
\end{tabular}

\subsubsection{Supporting sociability}

Friends and peers were mentioned many times in the interviews with child and teenager display users. It is important to be with friends, and using the display is usually something that is done in smaller or bigger groups. The display supports group activities through its big size, which allows an unobstructed view for groups of 3-5 and by offering games and services that suit group activities well (quotes 6.1/5 and 6).

Someone playing with a display interests people, who are drawn quickly to the display to watch others play (see quote 6.1/7). This "honey pot effect" is a well-known phenomenon in public display research (e.g., Müller et al. 2012). Some games can be played together, and collaboration is profitable, while in others, co-players have supportive roles. Users also developed their own gaming practices for group sessions with the displays, for example, competing with friends, who are playing the game on the other side of the double-sided display (quote 6.1/8). However, the current display technology does not support multi-touch, which hinders group playing activities. The importance of supporting sociability is also reflected in the fact that the public display is selected for entertainment purposes while with friends, but when the interviewees spent time alone in the space, they usually preferred their personal smart phones for entertainment purposes (quotes 6.1/9 and 6.1/10).

\begin{tabular}{cl}
\hline$\#$ & Quote \\
\hline $\mathbf{6 . 1 / 5}$ & And it is easy to be there because it is more spacious... You can be there with many others. (User, 9 yrs) \\
\hline
\end{tabular}




\begin{tabular}{cl}
\hline $\mathbf{6 . 1 / 6}$ & $\begin{array}{l}\text { If you have a friend, it [playing with the display] is probably more fun. Almost everything is more fun with a } \\
\text { friend. (User, } 11 \text { yrs). }\end{array}$ \\
\hline $\mathbf{6 . 1 / 7}$ & Sometimes it is like a magnet. When someone is playing with it, others gather there (User, 12 yrs) \\
\hline $\mathbf{6 . 1 / 8}$ & $\begin{array}{l}\text { We noticed when we went with a friend to play the UFO game, there were people on the other side of the } \\
\text { display also playing. And you can see others' names, who are also playing the game in the display. And when } \\
\text { they are suddenly moving somewhere, you are able to see that. So we asked, "Are you playing the UFO game } \\
\text { or the space game as well?" And they said, "Yes, we are." And usually the guns you use for shooting are next } \\
\text { to each other so we started to shoot each other for a joke. (User 9 yrs) }\end{array}$ \\
\hline $\begin{array}{l}\text { [When we are waiting at the swimming center with our classmates], we don't usually use our own smart } \\
\text { phones, but we play together [with the UBI display]. (User, 14 yrs) }\end{array}$ \\
$\begin{array}{l}\text { When I am alone, I prefer my phone, but when I am with friends, I prefer to play with the public display so } \\
\text { everybody can participate. (User, } 19 \text { yrs) }\end{array}$
\end{tabular}

\subsection{Users decoding technology within a negotiated reading}

\subsubsection{Unusable/usable technology}

Another important factor from the users' perspective is the usability of the public displays. Displays should be easy and intuitive to use, even for children. Usability is related to the user interface of the display itself and to each service offered. According to many user interviews, usability was accomplished well in the project. The displays were variously described as easy to use and learning to use them mostly happened by seeing someone else using it. For example, parents rarely taught their children to use the system (quotes 6.2/1 and 6.2/2).

Usability as a concern was also raised by inhabitants. Usability is a self-evidently required part of public technology, and problems are easily noticed. Poor usability of the first user interface version of the display raised debate in the discussion forum among inhabitants (quote 6.2/3). However, usability was improved in each new launched version, and new versions were launched each year during the first three years of the project. Nevertheless, some usability problems were still witnessed in the UBI project, indicated by users not finding services or applications available. This happened, for example, with attempts to combine mobile phones and the public display. According to the developers, using these apps required the user to pair the devices first, which turned out to be too laborious and difficult. The applications with distributed user interfaces remained short-term experiments in the public displays and were removed from the system due to the lack of use.

\begin{tabular}{cl}
\hline$\#$ & Quote \\
\hline $\mathbf{6 . 2 / 1}$ & $\begin{array}{l}\text { Boys have been able to use it well. They don't need any guidance or help. They can do it pretty much. (Parent } \\
\text { of } 2 \text { users, } 10 \text { yrs })\end{array}$ \\
\hline $\mathbf{6 . 2 / 2}$ & It is easy to use the UBI displays. (User, 10 yrs) \\
\hline $\mathbf{6 . 2 / 3}$ & $\begin{array}{l}\text { If a reporter has to be familiarized with the device that is set there for all the people to use, isn't there } \\
\text { something wrong with the device? Shouldn't it be working so that everybody was able to use it and it doesn't } \\
\text { require any learning? (Discussion forum writer \#3) }\end{array}$
\end{tabular}

\subsubsection{Useless/useful services}

The developers concluded in the interviews that for the users in a public display project the utility of the services is very significant. Although other aspects might be interesting for the researchers and developers, the services and their found usefulness will eventually determine whether the displays are used or not (quote 6.2/4). However, despite this acknowledgement, there were problems in providing useful services. The inhabitants complained about the lack of them. Utility seemed to be emphasized especially among the adult display users and other citizens; it was rarely mentioned by the younger display users. Utility of the services was also mentioned by the parents of the (child) display users in the field interviews; parents considered games that have educational elements and share useful information. Writers in the discussion forum of the local newspaper quite aggressively 
asked for useful services: The writers maintained that users and their needs should act as the starting point of the design, and the services should be meaningful with up-to-date content (quote 6.2/5). At the same time, the value of the games was not understood, but the utility of the services seemed to refer to serious content (quote 6.2/6).

\begin{tabular}{|c|c|}
\hline \# & Quote \\
\hline $6.2 / 4$ & $\begin{array}{l}\text { It has become clear [during this project] what is the true need and the utility of this kind of infrastructure and } \\
\text { the services it provides. Usability is important, of course, but the utility is even more important when we talk } \\
\text { about this sort of infrastructure. When you think that you are able to do all sorts of things with your } \\
\text { smartphone these days. So what is the added value of this kind of large display? If you are not thinking only } \\
\text { about the digital signage, where you advertise or promote some public service, but the interactive services. } \\
\text { (Developer \#1) }\end{array}$ \\
\hline $6.2 / 5$ & $\begin{array}{l}\text { Shouldn't you have figured out some reasonable content for that first? The first sight is the most important, if } \\
\text { it is not yet familiar for the UBI men. You fucked up with that "testing". The displays were so expensive that } \\
\text { you could have thought of some meaningful content there. --- (Discussion forum writer \#1) }\end{array}$ \\
\hline $6.2 / 6$ & $\begin{array}{l}\text { Does the developer team understand the possibilities? At least the hangman game is not one of them. UBI } \\
\text { displays should provide some real up-to-date information instead of the advertisements and ostensible } \\
\text { interaction. (Discussion forum writer \#2) }\end{array}$ \\
\hline
\end{tabular}

\subsection{Users decoding technology within opposing reading}

\subsubsection{Too public}

As described, playing with the public display attracts an audience. The visibility of the user's actions to others raises privacy as a relevant issue. Although using the public display is often social, having others watch one play does not always feel positive for the user (quote 6.3/3). Having an audience puts the player on a stage, and using the display becomes a public action. A 9-year-old female student compared using the public display to being at the front of the class. Thus, using the display requires courage with the consequence that the shyest ones do not dare to use the display at all (quote 6.3/1). Playing games in groups of friends is different from having unknown people watching and commenting on one's actions (quotes 6.3/2 and 6.3/4). The need for privacy when using the display came up during the interviews with the children who primarily used the display in the school context. In the swimming center context, privacy was mentioned only when adults were interviewed. In the school context, the privacy of the display usage was valued on the level that most of the users preferred using the display surface placed more privately toward the wall of the two-sided display installation.

\begin{tabular}{cl}
\hline$\#$ & Quote \\
\hline $\mathbf{6 . 3 / 1}$ & $\begin{array}{l}\text {.. The ones who everybody know, they are usually more on the display, because they like to use it more... } \\
\text { Meaning that those who are not familiar with everybody do not like to be in front of the class or there [on the } \\
\text { display]. (User, } 9 \text { yrs) }\end{array}$ \\
\hline $\mathbf{6 . 3 / 2}$ & $\begin{array}{l}\text { Sixth and fifth graders always try to annoy and talk big to the younger students. They often come and say } \\
\text { something mean or something. It would be easier if it [the display] was placed somewhere more private. } \\
\text { (User, } 9 \text { yrs) }\end{array}$ \\
\hline $\mathbf{6 . 3 / 3}$ & $\begin{array}{l}\text { It is two-sided. The other side faces the open lobby area, where everybody can see, and the other side faces } \\
\text { the wall and the janitor's office. Usually if someone is on the lobby side display, many people come to watch... } \\
\text { I prefer the one on the janitor's side. (User, 9 yrs) }\end{array}$ \\
& $\begin{array}{l}\text { It depends on what you are doing with it. If you are playing some worm game, you may feel that you are a } \\
\text { lonely young person. But if you are playing with a group, the embarrassment decreases, and it's a lot of fun. } \\
\text { Then you don't care what others are thinking. That's cool. (User, } 19 \text { yrs). }\end{array}$
\end{tabular}

\subsubsection{Dirty technology}

One perhaps unanticipated issue among users is hygiene, which came to play an important role in the public interactive touch screen installations. The need to clean touch screen surfaces became obvious, 
but maintenance problems occurred. The notion of dirty display surfaces was mentioned in developer and user interviews, as well as on social media (quotes 6.3/5, 6.3/6, and 6.3/8). In the interviews, the developers stated that users expect clean displays. Users in the field interviews were worried about hygiene, too. Users expressed their disgust with dirty displays and even a fear of infectious diseases spreading through the touch screen panels. The dirt on the display surface seemed to influence the usability of the system (quotes 6.3/5, 6.3/6, and 6.3/7).

The developers received similar feedback from inhabitants. Cleanliness became an issue at the beginning of the project through vandalism. The outdoor displays were occasionally damaged during the night, for example, with spit and stickers. After the first incidents, the developers hired a cleaning service to take care of the displays regularly. In the quotation $6.3 / 6$, a developer describes feedback from citizens.

\begin{tabular}{cl}
\hline$\#$ & Quote \\
\hline $\mathbf{6 . 3 / 5}$ & Ifeel disgusted that everybody touches the screen. (Parent of a user, 15 yrs) \\
\hline $\mathbf{6 . 3 / 6}$ & $\begin{array}{l}\text { So we got answers, like who would dare to touch it, when you never know who has touched it before, and } \\
\text { there has been spit and so on. (Developer \#6) }\end{array}$ \\
\hline $\mathbf{6 . 3 / 7}$ & $\begin{array}{l}\text { When some smaller pupils have just come out of lunchroom and their fingers are a bit dirty, so the display is } \\
\text { sometimes awfully dirty... So that you are not even able to touch it properly because there is this layer of } \\
\text { grease on the top (2 Users, } 13 \text { yrs) }\end{array}$ \\
\hline $\mathbf{6 . 3 / 8}$ & ... No one bothers to touch those malfunctioning filthy screens. (Discussion forum writer) \\
\hline
\end{tabular}

\subsubsection{Unreliable technology}

Users expected the UBI displays to be reliable, but this expectation was not always fulfilled. Reliability problems were still present six years after the launch, although not as frequently as in the beginning. For users, it was annoying when the displays did not function as they were supposed to. Almost all of the interviewed users had witnessed this event. One developer described the worst-case scenario in which a user first has to cope with the dirty display surface and then notices the display is not functioning at all (quote 6.3/9).

Reliability was highlighted several times in the data. It was brought up as well many times in the writings of the inhabitants in the discussion forum. The reliability of the displays is linked to the developers' value of doing research in the wild. Developers wanted to do research in the wild by bringing research demonstrations into the real world to test with "real" users. However, the inhabitants seemed to expect ready-made commercial products and complained constantly about the incompleteness of the displays. In a quotation, a writer in the discussion forum defends the display system by highlighting its purpose as a research prototype (quote 6.3/10).

\begin{tabular}{cl}
\hline$\#$ & Quote \\
\hline $\mathbf{6 . 3 / 9}$ & $\begin{array}{l}\text {... When the townie goes there and there is the spit on the screen and the USB route of the panel has broken } \\
\text { down from the central unit. So although the user would exceed the threshold, tries not to touch the spit, and } \\
\text { then the panel is not working. (Developer \#6) }\end{array}$ \\
\hline $\mathbf{6 . 3 / 1 0}$ & $\begin{array}{l}\text { What is this complaining about uncompleted and untested displays? They are tested now with US, OULU } \\
\text { CITIZENS, as you can read from the project website. It is better to test with an ordinary inhabitant than with } \\
\text { engineers in a dark laboratory, isn't it? (Discussion forum writer \#4) }\end{array}$
\end{tabular}

\subsubsection{Disturbing technology}

Users expected calmness from the displays. The displays should not visually or audibly disturb passers-by wherever they are. However, users and inhabitants interpreted the technology as disturbing. Sounds and too bright lights were found to fight against the calmness of the technology (quotes 6.3/11 and 6.3/12).

\section{\# Quote}




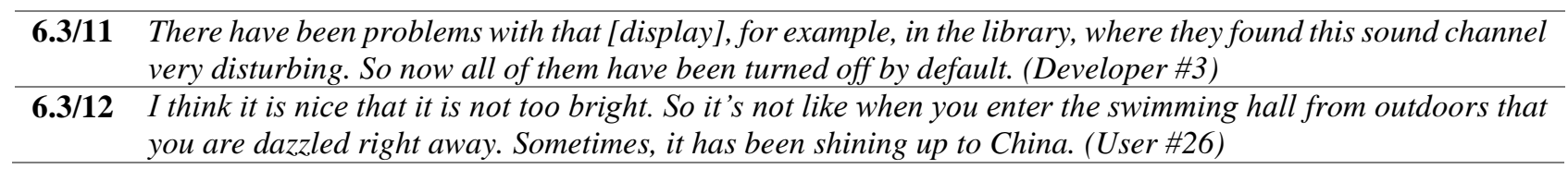

\section{Conflicts and convergence}

In this section, we discuss the conflicts and then the compatibilities that can be identified between the cultural values of the developers and the stakeholder requirements as well as the users' interpretations. Specific cultural values shaped the urban computing project and the technology design, while diverse stakeholder groups interpreted and approached the project and its outcomes in distinct ways. Some of the developer team's cultural values were very much in line with the stakeholders' requirements and created cohesion. However, many of the developers' values caused conflicts with others' requirements, generated tension between the groups, and required negotiations and compromises. These findings are discussed in more detail. We focus mostly on the interesting conflicts we identified and discuss the convergences more superficially.

\subsection{Conflicts between developers' cultural values and stakeholders' requirements and interpretations}

The developers were in charge of the whole project. They had to cope with the distinctive requirements, needs, expectations, and desires of other stakeholder groups and adapt their own needs and visions. Next, we elaborate the conflicts related to the developers' cultural values.

\subsubsection{World-class research/cutting-edge technology versus high visibility/reliability and useless/unreliable technology}

The developers' research-related values caused most of the conflicts between the stakeholder groups in the project. The fundamental challenge was that the developer-researchers were conducting research and used the displays as test-beds in the wild for the experiments, while the citizens, advertisers, and the municipality expected a ready-made, tested, and polished set of useful, usable services in reliable displays. The developers characterized the displays as "research platforms" and "research prototypes" and highlighted that they should be considered as such, and not as ready-made commercial products. Cutting-edge technology and technological innovations were the driving force for the developer-researchers from the beginning of the project. These innovations were seen as the premise for the research contribution. The hardware had to be robust and customable, and the software could not be "off the shelf." It had to be innovative and complex.

As the solutions were novel, problems with reliability occurred. These problems caused conflicts with users' and advertisers' requirements for reliable technology: The advertisers sought smooth visibility of their ads, and the users just wanted to be able to use the services without interruptions. Overall, the citizens, advertisers, and municipality did not understand the nature of the display project as an iterative research process in which the displays could be modified and improved according to feedback and suggestions (quote 7.1/1). Citizens even expressed a hostile attitude toward spending money on this kind of thing, that is, on research (quote 7.1/2).

The content of the services was a disappointment to the users. They felt that the services were not really designed for their needs and purposes. In addition, the municipality expected services that would benefit everybody. However, the developer group did not see enough research contribution in coding basic services merely to serve the citizens. It was interesting to observe that among the users' views, what constituted a useful service varied substantially. Some seemed to prefer serious, informative content, while others seemed to prefer entertainment content to kill time. Currently, the entertainment content is the only type of content constantly in use. 
Another clearly problematic aspect from the viewpoint of research was that the advertisers expected full-screen advertisement time for their ads, while the developers sought high visibility for the interactive research applications. The interactive services were the main interest for the developerresearchers. For example, the usage statistics of the services were collected, and the data was utilized for research. As a result of arm-twisting with the advertisers, the developers had to change the face detection-based mode switching (between the full-screen advertisement mode and the interactive screen mode) to touch-based mode switching. This resulted in a decrease in the interactive service use rate, which was harmful for the research purposes. In the quotation 7.1/3, a developer explains the problem of the visibility of the interactive services and how it impacts research.

\begin{tabular}{cl}
\hline$\#$ & Quote \\
\hline 7.1./1 & $\begin{array}{l}\text { It is extremely difficult to use them. The user interface is lousy, the delay is too long and the applications are } \\
\text { full of bugs. You cannot find information there although you dug patiently. What on earth is this? Why? Who } \\
\text { is responsible? Was any beta-testing performed with these information displays before they were published?? } \\
\text { Now they are a parody of Oulu IT!! (Discussion Forum writer) }\end{array}$ \\
\hline 7.1./2 & $\begin{array}{l}\text { There you have inventors, nobody is interested, and you thought it was such an important and smart idea. } \\
\text { Shouldn't we have had some other use for the money in this village, for example, struggling health care. } \\
\text { (Discussion Forum writer \#7) }\end{array}$ \\
& $\begin{array}{l}\text { We made this sort of simple playlist-based system [for ads], which functions well in what it does. But it } \\
\text { hidn't have the advertisement channel, I could just set the research service, which I want to study, in full- } \\
\text { screen on every display and gain directly like thousand users to try it, but as it is behind the advertisement, it } \\
\text { would get lost in the application menu anyway. So we sort of tied our own hands, but we didn't know it back } \\
\text { then. (Developer \#3) }\end{array}$
\end{tabular}

\subsubsection{Researchers'freedom versus useful services/reliability and unreliable/useless technology}

The importance of doing research and being a researcher became the guiding light for the developer team. Being a researcher meant being something other than a "code slave": Researchers were more independent actors and had more freedom. Conflicts occurred even within the developer team. The researchers wanted to concentrate on the research tasks, but at the same time, the researchers had to take care of the display network, which demanded constant maintenance. The maintenance took time from the actual research work, and nobody wanted to do it. The reluctance to engage with maintenance work resulted in conflicts with the users' expectations of reliable services. There were cases in which some of the displays had crashed, and nobody fixed them in time. Another issue related to researchers' freedom was the quality of the services. Appealing to the researchers' freedom, the developers did not want to develop services merely for the purpose of serving citizens. The developers did not see enough research contribution in developing very basic services. The developers wanted to decide themselves what to study and how to study it without input from other stakeholders. The developers often wanted to concentrate on technological solutions rather than on service design issues. Users', inhabitants', and municipality representatives' suggestions were not always in line with the expected research contribution and personal research interests. Developing the displays for the inhabitants seemed to remain less important.

\subsubsection{Power in numbers versus unusable technology}

An interesting detail in the developer team was the "power in numbers" mindset. This related to respecting statistical data and research over qualitative data and listening to the users, whilst aiming at the same time to offer a larger number of services and displays and larger screens. Although the developers tried to develop as many services as possible, the quantity might have affected their quality. If the developers had concentrated on fewer services instead of trying to implement as many 
as possible, the quality might have been better. Moreover, the large number of services created a complex menu structure in the user interface that likely affected usability and contributed to the formation of the users' first impression of a complex uninviting user interface.

\subsubsection{Recognition versus disturbing technology}

The municipality valued a coherent cityscape. The cityscape working group, which contained mainly architects, decided how the city furniture should look. The group required that the displays should blend into the city environment in appearance, color, and shape. This requirement contradicted the developers' vision of inviting and outstanding displays. The need for calm technology was also brought up by the display users and inhabitants. Users did not want the displays to be too striking in the cityscape or public buildings. The users did not want the displays to be noisy or too bright. The complaints from the inhabitants about bright lights or annoying sounds also resulted in modification of the displays, for example, shutting down the loudspeakers. Table 2 summarizes the conflicts identified in the project.

Table 2 Summary of the findings for conflicts between the developers' cultural values and other stakeholder groups' requirements and interpretations

\begin{tabular}{|c|c|c|}
\hline Developer values & $\begin{array}{l}\text { Conflicting } \\
\text { requirements and } \\
\text { interpretations }\end{array}$ & Explanation \\
\hline & $\begin{array}{l}\text { Municipality: } \\
\text { USEFUL SERVICES }\end{array}$ & $\begin{array}{l}\text { The municipality expected useful services for citizens, while the } \\
\text { developers did not see enough research contribution merely in } \\
\text { developing services for citizens. }\end{array}$ \\
\hline & $\begin{array}{l}\text { Advertisers: } \\
\text { HIGH VISIBILITY }\end{array}$ & $\begin{array}{l}\text { The advertisers demanded visibility for their ads, while the } \\
\text { developers required cutting-edge technological solutions, which } \\
\text { turned out to be vulnerable and caused interruptions. The developers } \\
\text { needed visibility for their interactive research applications while } \\
\text { doing research in the wild, while the advertisers demanded more } \\
\text { visibility for their ads, which reduced the visibility of the interactive } \\
\text { research applications. }\end{array}$ \\
\hline & $\begin{array}{l}\text { Advertisers: } \\
\text { RELIABILITY }\end{array}$ & $\begin{array}{l}\text { The advertisers sought risk-free advertising with traditional digital } \\
\text { signage, while the developers were doing research and experimenting } \\
\text { with innovative solutions for advertising. Interruptions in the service } \\
\text { created a bad reputation for the displays as an advertising forum. }\end{array}$ \\
\hline & $\begin{array}{l}\text { Users } \\
\text { USELESS SERVICES }\end{array}$ & $\begin{array}{l}\text { Users expected useful services, while the developers did not see } \\
\text { enough research contribution merely in developing services for users. }\end{array}$ \\
\hline & $\begin{array}{l}\text { Users } \\
\text { UNRELIABLE } \\
\text { TECHNOLOGY }\end{array}$ & $\begin{array}{l}\text { Users expected reliable technology, while the developers sought a } \\
\text { forum for testing applications for research purposes and saw the } \\
\text { system as a research prototype and not as ready-made commercial } \\
\text { product. }\end{array}$ \\
\hline & $\begin{array}{l}\text { Developers: } \\
\text { Research versus } \\
\text { maintenance }\end{array}$ & $\begin{array}{l}\text { Tensions within the developer team about the compulsory } \\
\text { maintenance work that took time from research. }\end{array}$ \\
\hline & $\begin{array}{l}\text { Municipality: } \\
\text { USEFUL SERVICES }\end{array}$ & $\begin{array}{l}\text { The developers did not want to develop services for citizens if the } \\
\text { services were not interesting from a research perspective. }\end{array}$ \\
\hline & $\begin{array}{l}\text { Users: } \\
\text { USELESS SERVICES }\end{array}$ & $\begin{array}{l}\text { The developers' personal research interests and useful services for } \\
\text { users did not match. }\end{array}$ \\
\hline & $\begin{array}{l}\text { Users: } \\
\text { UNRELIABLE }\end{array}$ & $\begin{array}{l}\text { Users expected reliable services and functionality, while the } \\
\text { developers used the displays as test beds for their experiments and } \\
\text { did not want to spend time on maintenance, as it was time away from } \\
\text { their personal research. }\end{array}$ \\
\hline POWER IN & Users: & The developers thought the more services the better, which caused a \\
\hline \multirow[t]{2}{*}{ NUMBERS } & $\begin{array}{l}\text { UNUSABLE } \\
\text { TECHNOLOGY }\end{array}$ & $\begin{array}{l}\text { complex user interface structure and decreased the usability of the } \\
\text { services. }\end{array}$ \\
\hline & $\begin{array}{l}\text { Municipality: } \\
\text { AESTHETICS }\end{array}$ & $\begin{array}{l}\text { The developers sought attention for the displays within the city to } \\
\text { gain more users for the interactive research services. The }\end{array}$ \\
\hline
\end{tabular}


municipality wanted to maintain a coherent streetscape and did not want the displays to stand out.

Users: Users did not want the displays to disturb people with lights or noise.

DISTURBING

The developers wanted visibility for the displays but were forced to

TECHNOLOGY make compromises.

\subsection{Compatibilities between cultural values and stakeholders' technology-related requirements and interpretations}

In addition to the conflicts, there were compatibilities between the values, requirements and interpretations of the identified stakeholder groups. Some of the developer values were in line with the requirements of the other stakeholder groups. In general, the advertisers', municipality's, and users' requirements and expectations were similar. Next, these findings are discussed.

\subsubsection{Researchers' freedom/power in numbers and offering entertainment/supporting sociability}

In contrast to the other stakeholders' requirements for "useful" services, the developers ended up implementing a number of simple games on the displays. The developers chose freely what to implement, in accordance with the value they placed on researcher freedom. In addition, power in numbers was influential in the background as the developers aimed to develop many simple services instead of concentrating on only one or two services. This strategy was successful in the sense that especially younger users found that the displays were entertaining and supported their social practices. In the following quotation, a developer describes how a game, developed as a course assignment by students, ended up being one of the most popular applications on the displays (quote 7.2/1).

\begin{tabular}{cl}
\hline$\#$ & Quote \\
\hline $\mathbf{7 . 2 / 1}$ & $\begin{array}{l}\text { Yeah, the Wordster, it was made by a student group. I was an assistant in that course. I made the map as a } \\
\text { prototype, and the Wordster game had to use the same framework... The Wordster game ... became one of } \\
\text { the most popular apps at least at that moment. (Developer \#4) }\end{array}$ \\
\hline
\end{tabular}

\subsubsection{Useful services/reliability/aesthetics and useless/unreliable/disturbing technology}

Users, citizens, and advertisers did not seem to value or understand the research aspect of the project. Instead, some among these groups even seemed to be hostile toward research. They all expected reliability instead. The advertisers wanted to gain as much visibility as possible for their ads, and the users wanted to be able to use the services smoothly. They took the displays as ready-made products for public use; the users did not value the displays as research test-beds or platforms. The users were not enthusiastic about the innovative technological solutions. For instance, the users never really found the novel solutions of distributed user interfaces, and the advertisers were not interested in investing in novel adaptive advertising (quote 7.2/2).

Users, inhabitants, and the municipality all wanted useful services for everybody to use in the city. The municipality wanted to change the map signs to a digital platform, so that the city could get rid of the old signs. Users asked for context-aware services that they would benefit from in daily life. However, as has been pointed out, there were also conflicts and controversy among these groups. The users did not all share the idea of what constitutes a useful service. However, all these groups valued the calmness of the technology. The municipality concentrated on the calmness of the physical displays by choosing the color and shape of the display stands. Users and inhabitants were worried about the audible and visual aspects, and demanded that the displays not be too bright or too loud.

\section{\# Quote}


7.2/2 ... And it is a fact that when it says "research" somewhere, it's often a curse for those big companies, if it doesn't concern their own product development. We had to highlight as much as possible that this was an exercise by an academic organization and bring out that we do academic research and try to develop solutions for the future... (Developer \# 7)

\section{Concluding discussion}

Drawing on the trajectory of a decade-long urban computing project in the wild, in this study we identified cultural values that shaped the project and its outcomes. In addition, we identified a number of stakeholders involved in the project and a variety of their technology-related requirements and interpretations. In some cases, the cultural values were shown to contribute to conflicts, while in other cases, compatibility emerged or was achieved. Next, we summarize the empirical results and then discuss the implications.

\section{Figure 3. here}

Fig. 3 Encoded developer values and stakeholder requirements and decoded user interpretations in the urban computing project

\subsection{Summary of the results}

This article analyzed how stakeholders' (advertisers and the municipality) requirements and developers' cultural values were encoded within the urban computing technology, the public display network. We also studied how users decoded the technology in different ways. Some of the users' interpretations were in line with the developers' encodings (preferred reading), others were not (opposite reading), and some were in between the two (negotiated meaning; see Fig. 3). In general, users and inhabitants, as well as the municipality, had similar requirements that did not align very well with the developers' research and innovation-oriented values. None of the other stakeholders valued research and innovations, and there even seemed to be some hostility toward research among them. The requirements and interpretations identified in relation to these groups had a very practical orientation, prioritizing usable, useful, and reliable services, as well as calmness of the displays. Advertisers valued reliability similarly as users but were mainly interested in the visibility of their own advertisements. The advertisers did not value technological innovations either, but wanted to play it safe.

The developers' cultural values driving the project caused many conflicts. First, the project ended up in a hurry and with a not-so-polished system that crashed at times due to the emphasis on experimenting with cutting-edge technology and conducting world-class research. The users' and inhabitants' disappointment related to the usefulness, usability, and reliability of the services was observable after the launch. This also caused bad publicity for the project, in the press and on social media. Problematic from the research point of view was also that the advertisers demanded more screen time for their advertisements, which reduced the visibility of the interactive content that was important to the researchers. The reduced visibility of the interactive content was problematic from the perspective of the adoption of the services in the city. The unreliable nature of the system, moreover, caused some advertisers to abandon the project, which was problematic from the funding perspective. Finally, although the developers wanted high visibility for their displays in the cityscape, the municipality and the users demanded calm technology that would not disturb people in any way. Overall, although the development project had a seemingly generic "for all" ethos, the various stakeholders' values, requirements, and interpretations pulled the focus in different directions. The trajectory of the project can be characterized as reactive, constantly shaped by these contesting influences.

Interestingly, we also found value evolution, as well as value conflicts, within the stakeholder groups. A value change took place in the developer team during the project's timespan as the team gradually emphasized and increasingly appreciated world-class research instead of local research and 
development work. However, this change caused tensions among the developer team members: There was tension between research and maintenance work. The developer-researchers did not want to be code slaves anymore but wanted to concentrate on doing their research. We also identified divergence among the users about what constitutes useful services for different users. The adult population in this study seemed to value serious, informative, and educational content, whereas the children preferred entertaining solutions for time-killing and socializing purposes. Definitely, school-aged or younger children in many ways constitute a different cultural group from adults. The take-away is that for studies in the wild one should be prepared for cultural and value diversity even among the stakeholders, for example, the users.

\subsection{Cultural values, stakeholder requirements, and user interpretations in community technology design}

The contribution of this article is a structured analysis and reflection on cultural issues in community technology design in the wild, with a focus on the role of developers' cultural values and other stakeholders' technology-related requirements and interpretations. Although researchers have examined cultural aspects of technology design (Flanagan et al. 2005; Iivari 2006; Sabiescu et al. 2014; Winschiers-Theophilus et al. 2015) and use (Lindtner et al. 2012; Martinviita et al. 2015; Ogan et al. 2012), many studies only engage superficially with cultural issues. In this respect, this study offers an in-depth analysis of cultural issues in a community technology design project, covering an analysis of values and requirements endorsed by different stakeholders. Additionally, this article sheds light on how cultural values are intermingled with a community technology design in the wild. To date, some scholars have argued that there may be cultural differences between designers and local user communities (Sabiescu et al. 2014; Winschiers-Theophilus et al. 2015). Studies on longterm multi-stakeholder projects have also pointed out a number of challenges (Cheverst et al. 2012; Clinch et al. 2011; Dalsgaard and Halskov 2010, Friday et al. 2012; Halkola et al. 2015; Memarovic 2015; Ståhlbröst et al. 2015; Taylor et al. 2013; Ylipulli and Suopajärvi 2013), while cultural analyses of such projects are limited. This study contributes by showing that not only designers and users or user communities with their (cultural) values shape the process, but that there is an even greater versatility of stakeholders and their (cultural) values and technology requirements and interpretations, which may further complicate the picture. In addition, such values are negotiated and evolve over time, even within the stakeholder groups.

This article proposes the encoding/decoding lens for understanding the dynamics of designing community technology. This lens enables an examination of how technological artefacts are encoded with various structures, practices, networks, relations, ideologies, assumptions, and infrastructures (Hall 1980) and how those influence the decoding process of the technology consumer, too. We studied the developers' values and the advertisers' and municipality's technology requirements encoded in the technology. At the other end of the coding process, we saw how users interpreted or decoded the technology. We descibed three decoding positions. The preferred reading follows the developers' initial intentions. In this study, two interpretations: (offering entertainment and supporting sociability) were classified in this category. In both interpretations, the users "understood" the developers' encodings. Opposing readings in this study were too public, dirty, unreliable, and disturbing technology. An opposing reading usually refers to a very critical stance toward the message being delivered and the analysis is usually inspired by the critical research tradition. In this study, the opposing readings of the technology were not that radical, although sometimes the users expressed a very hostile attitude toward the project and its outcomes. However, an analysis inspired by critical theory should be carried out to examine this issue in more detail.

As for understanding the cultural aspects, the study was inspired by the tradition of cultural anthropology, while strongly tied to the technology design context. In this article we advocate the interpretive approach to culture, within which culture is viewed as socially produced and reproduced. 
We also emphasizes that the view of culture as a static, shared pattern or whole should be abandoned. Instead, cultures should be viewed as plural, fragmented, emergent, and continuously open to interpretation (cf. Clifford and Marcus 1986; Czarniawska-Joerges 1992; Iivari 2006, 2010; Keesing and Strathern, 1994; Ortner, 1999). Thus, this study preferred to examine cultural aspects that shape technology design rather than a culture that is seen to shape technology design. The cultural aspects in this article were operationalized as the developers' shared but evolving cultural values. In addition, we considered other stakeholders' technology requirements and users' technology interpretations when confronting community technology in the wild. We see such requirements and interpretations as being underpinned by shared (cultural) values. They indicate a diversity of values of different stakeholder groups.

In this study, we concentrated on the cultural values of the researcher-developer team and examined the cultural aspects of their project (i.e., their project culture). The origins of the identified values are versatile. Many likely are derived from the local organizational culture, but others are shaped by the occupational or professional cultures the developers are members of. Some of the identified values are consistent with international independent research institutions (world-class research, researchers' freedom, and recognition). They can be seen to originate partially from engineering education (power in numbers) and partially from specific research field and topical research problems (cutting-edge technology). However, values are not viewed as a static, fixed, shared set that can be comprehensively captured, but instead as a plural and emergent constellation that is continuously open to interpretation and negotiation. Such negotiation takes place within stakeholder groups, as well as between them. Specifically interesting from the perspective of technology design is the compatibility or fit of these values. In the existing literature on technology design, this has been a recurrent theme, with an assumption that compatibility or fit is needed in order to succeed. This article shows both compatible and conflicting values that pulled the project in different directions. The trajectory of the project can be characterized as reacting to these contesting influences that shifted the project in an abundance of twists and turns. This study does not claim that cultural compatibility is a necessary ingredient of successful computing projects but instead maintains that such compatibility might be unrealistic or impossible to achieve. However, we also point out that such compatibility should be aimed for as many of the conflicts identified in this computing project were detrimental for the progress of the project.

In this article, cultural aspects were studied as shared values, and conflicts and compatibilities were identified in relation to those values. The compatibilities seemed to help the project progress on the jointly preferred path, whereas the conflicts made the project head in a direction not preferred by all and which in many cases was disadvantageous for the progress of the project. The case itself does not offer advice for how to deal with the conflicts, however. In this project, no explicit discussions of the values driving the design process were carried out during the project but those were revealed only through data analysis after the fact. The existing literature on culture and technology (e.g., Gallivan and Srite 2005; Iivari and Iivari 2011; Iivari 2006, 2010), however, enables some recommendations to be made. Culture studies in the context of technology design and use identified compatible culture types for various kinds of technologies and compatible implementation strategies to achieve fit between culture and technology. This necessitates cultural analysis, as well as negotiation and consideration of whether and how to change the cultural values or the technology in question. Technology is easier to fix than culture; thus, designers should try to carefully modify technology to align with the stakeholders' cultural values. Occasionally, this might be impossible, and then an open discussion of the stakeholders' values might be useful, while managing and intentionally changing cultural values is very difficult and possibly even unethical to achieve. It is also very important to acknowledge that there is a very complex, emergent, reciprocal relationship between culture and technology. That is, technology may modify and change the stakeholders' cultural values, whereas the stakeholders may also adapt and change the technology in many ways during its design and use to suit or fit their values. 
Table 3 Recommendations for cultural value analysis in community computing projects

\begin{tabular}{ll}
\hline When & What \\
\hline Before & A priori identification of stakeholders \\
& Open dialogue with stakeholders about values and requirements \\
& Identification of possible mismatches and conflicts of values and requirements \\
& Resolving them or seeing them as design constraints \\
During & $\begin{array}{l}\text { Identification of in vivo stakeholders } \\
\text { Open dialogue regularly (e.g., yearly) with stakeholders about values and requirements }\end{array}$ \\
& $\begin{array}{l}\text { Identification of possible mismatches and conflicts of values and requirements } \\
\text { Resolving them or seeing them as design constraints }\end{array}$ \\
\hline After & $\begin{array}{l}\text { Post hoc identification of stakeholders } \\
\text { Collaborative, retrospective analysis and evaluation of emerged values, their mismatches, conflicts and } \\
\end{array}$ \\
& value evolution, and their impacts on the project success
\end{tabular}

We recommend such cultural value considerations for community technology design projects before, during, and after their execution (see Table 3). Here, we derive inspiration from methods such as value-sensitive and value-led design (Iversen et al. 2010; Miller et al. 2007). Value-sensitive design helps identify the benefits and harms of a technology for different stakeholder groups. They are to be mapped to human values with ethical import. Potential value conflicts or tensions should be observed early during the design process and addressed as design constraints (Miller et al. 2007). Value-led design, furthermore, guides even more explicitly to a dialogic process among the stakeholders, with whom the values driving the design and action should be discussed and negotiated collaboratively (Iversen et al. 2010). We assume that a more explicit handling of values might have helped to alleviate the tensions that emerged during the design process examined in this study. Value-sensitive or valueled design and evaluation sessions could have been introduced during the project to address the challenges encountered: to negotiate a shared understanding or even compromise to satisfy everyone somewhat. This was not done in this case. However, we recommend that in urban computing projects, as well as in community technology design projects more generally, the values of all potential, identifiable stakeholder groups should be discussed before the project. Studies on the stakeholder groups are warranted from a value perspective. Possible mismatches and conflicts should be openly discussed beforehand. In addition, one should also acknowledge that new stakeholder groups may emerge and the values identified may change in time. Thus, the analysis of values and their influences should continue during the project. Open discussion and negotiation of the values of each stakeholder group and the possible value conflicts could be organized regularly in projects, for example, yearly. Finally, such values and their evolution during a project should be retrospectively examined. Such reflection and analysis could provide valuable insights for future work. By examining the problems and conflicts, one might become better prepared to handle them in the future.

\subsection{Limitations and pathways for future work}

In this article, we consciously took the developers' perspective. A more comprehensive picture of cultural values would be gained through interviewing other parties in more depth. However, we concentrated on the developers' perspective as they were the main actor group in the project and their cultural constellation deserves more attention in the research literature. In the future, the cultural values of other stakeholder groups should be examined in more detail. In addition, we did not conduct a value analysis with the developers but identified the values in data collected beforehand. Valueoriented interviews or workshops could have revealed even a wider spectrum of (cultural) values among the developers. Overall, this study opens up interesting paths for subsequent studies addressing computing projects in the wild. We frame such computing projects as fluid settings of a great variety of stakeholders with a multiplicity of values, requirements, and interpretations. We encourage other 
researchers, too, to adopt a cultural lens for making sense of such settings and the complexity involved in them.

\section{REFERENCES}

Adriansen H K (2012) Timeline interviews: A tool for conducting life history research. Qualitative Studies, 3(1): 40-55

Ajmal M M, Koskinen K U (2008) Knowledge transfer in project-based organizations: an organizational culture perspective. Project Management Journal, 39(1): 7-15.

Allaire Y, Firsirotu M E (1984) Theories of organizational culture. Organization Studies, 5(3):193226

Brown J S, Collins A, Duguid P (1989) Situated cognition and the culture of learning. Educational researcher, 18(1): 32-42

Cheverst K, Taher F, Fisher M, Fitton D, Taylor N (2012) The design, deployment and evaluation of situated display-based systems to support coordination and community. Ubiquitous Display Environments, Series: Cognitive Technologies: 105-124

Clifford J, Marcus G (Eds.) (1986) Writing culture: the poetics and politics of ethnography. Berkeley: University of California Press.

Clinch S, Davies N, Friday A, Efstratiou C (2011) Reflections on the long-term use of an experimental digital signage system. In: Proceedings of UbiComp'11: 133-142

Czarniawska-Joerges B (1992) Exploring Complex Organizations. A Cultural Perspective. Newbury Park: Sage Publications

Dalsgaard P, Halskov K (2010) Designing urban media façades: cases and challenges. In: Proceedings of $C H I$ 2010:2277-2286

Flanagan M, Howe D C, Nissenbaum H (2005) Values at play: Design tradeoffs in socially-oriented game design. In: Proceedings of CHI 2005:751-760

Friday A, Davies N, Efstratiou C (2012) Reflections on long-term experiments with public displays. Computer 45(5):34-41

Gallivan M, Srite M (2005) Information Technology and Culture: Merging Fragmented and Holistic Perpectives of Culture. Information \& Organization 15(2):295-338

Geertz C (1973) The interpretation of cultures: selected essays. New York: Basic Books

Giorgi S, Lockwood C, Glynn M A (2015) The Many Faces of Culture: Making Sense of 30 Years of Research on Culture in Organization Studies. The Academy of Management Annals, 9(1): $1-54$

Grint K, Woolgar S (1997) The Machine at Work. Technology, Work and Organization. Cambridge: Polity Press

Halkola E, Iivari N, Kuure L (2015) Infrastructuring as social action. In: Proceedings of ICIS2015. Hall S (1980) Encoding/decoding. In: Hall S, Hobson D, Lowe A, Willis P (Ed.) Culture, Media, Language: Working Papers in Cultural Studies, 1972-79, London, Hutchinson, pp 128-138.

He H A, Memarovic N, Sabiescu A, de Moor A (2015) CulTech2015: cultural diversity and technology design. In: Proceedings of C\&T: 153-156

Iivari N (2006) 'Representing the User' in Software Development - A Cultural Analysis of Usability Work in the Product Development Context. Interacting with Computers 18(4): 635664

Iivari N (2010) Culturally compatible usability work - An interpretive case study on the relationship between usability work and its cultural context in software product development organization, Journal of Organizational and End User Computing, 22(3):40-65

Iivari N (2005) Usability Specialists-'A Mommy Mob', 'Realistic Humanists' or 'Staid Researchers'? An Analysis of Usability Work in the Software Product Development. In: IFIP Conference on Human-Computer Interaction (pp. 418-430). Springer Berlin Heidelberg. 
Iversen O S, Halskov K, Leong T W (2010) Rekindling values in participatory design.

In: Proceedings of PDC:91-100

Kappos A, Rivard S (2008) A three-perspective model of culture, information systems, and their development and use, MIS Quarterly, 32(3): 601-634

Keesing R, Strathern A (1998) Cultural Anthropology. A Contemporary Perspective (3rd ed.). Fort Worth: Harcourt Brave College Publishers

Kroeber A, Kluckhohn C (1952) Culture: a critical review of the concepts and definitions. Cambridge: Harvard University Press

Kukka H, Luusua A, Ylipulli J, Suopajärvi T, Kostakos V, Ojala T (2014) From cyberpunk to calm urban computing: Exploring the role of technology in the future cityscape. Technological Forecasting \& Social Change 82:29-42

Lave J, Wenger J (1991) Situated learning: Legitimate peripheral participation. Cambridge: Cambridge University Press

Lindtner S, Anderson K, Dourish, P (2012) Cultural appropriation: information technologies as sites of transnational imagination. In: Proceedings of CSCW:77-86

Marcus A, Gould E W (2000) Crosscurrents: cultural dimensions and global Web user-interface design. Interactions, 7(4): 32-46

Martinviita A, Kuure L, Luoma P (2015) Do we speak the same language?: design goals and culture clashes in an online forum for young people. In: Proceedings of C\&T: 69-78

Memarovic N (2015) Understanding future challenges for networked public display systems in community settings. In: Proceedings of C\&T: 39-48

Memarovic N, Langheinrich M, Cheverst K, Taylor N, Alt F (2013) P-LAYERS - A layered framework addressing the multifaceted issues facing community-supporting public display deployments. ACM Transactions on Computer-Human Interaction 20(3): article 17

Miller J K, Friedman B, Jancke G, Gill B (2007) Value tensions in design: the value sensitive design, development, and appropriation of a corporation's groupware system. In: Proceedings of GROUP: 281-290

Müller J, Walter R, Bailly G, Nischt M, Alt F (2012) Looking Glass: A field study on noticing interactivity of a shop window. In: Proceedings of CHI 2012:297-306

Myers M D, Newman M (2007) The qualitative interview in IS research: Examining the craft, Information and Organization, 17: 2-26

Ogan A, Walker E, Baker R S, Rebolledo Mendez G, Jimenez Castro M, Laurentino T, de Carvalho A (2012) Collaboration in cognitive tutor use in Latin America: Field study and design recommendations. In: Proceedings of CHI 2012: 1381-1390

Ojala T, Kukka H, Lindén T, Heikkinen T, Jurmu M, Hosio S, Kruger F (2010) UBI-hotspot 1.0: Large-scale Long-term Deployment of Interactive Public Displays in a City Center. In: Proceedings of ICIW: 285-294

Ortner S B (Ed) (1999) The Fate of Culture. Geertz and Beyond. Berkeley: University of California Press

Ouchi W, Wilkins A (1985) Organizational Culture. Annual Review of Sociology 11: 457-483

Sabiescu A G, David S, van Zyl I, Cantoni L (2014) Emerging spaces in community-based participatory design: reflections from two case studies. In: Proc. PDC: 1-10

Schein E (1985) Organizational culture and leadership, 2nd edn. San Francisco: Jossey-Bass

Sheridan J, Chamberlain K, Dupuis A (2011) Timelining: visualizing experience. Qualitative Research, 11(5): 552-569

Ståhlbröst A, Bergvall-Kåreborn B, Ihlström Eriksson C (2015) Stakeholders in Smart City Living Lab Processes. In: Proceedings of AMCIS'15: 1-11

Suopajärvi T, Ylipulli J, Kinnunen T (2012) "Realities behind ICT Dreams": Designing a Ubiquitous City in a Living Lab Environment. International Journal of Gender, Science and Technology, 4(2): 231-252 
Taylor N, Cheverst K (2010) Creating a rural community display with local engagement. In: Proceedings of DIS'10: 218-227

Taylor N, Cheverst K (2009) Supporting community awareness with interactive displays. Computer 45(5): 26-32

Taylor N, Cheverst K, Wright P, Olivier P (2013) Leaving the wild: Lessons from community technology handovers. In: Proceedings of CHI 2013: 1549-1558

Tolvanen E, Jylhä M (2005) Alcohol in life story interviews with Finnish people aged 90 or over: Stories of gendered morality. Journal of Aging Studies, 19(4): 419-435

Van Maanen J, Barley, Stephen R. (1984) Occupational communities: Culture and control in Organizations. In: Barry M. Staw, L. L. Cummings (ed). Research in Organizational Behavior Vol. 6. Greenwich: JAI Press.

Van Marrewijk A (2007) Managing project culture: The case of Environ Megaproject. International Journal of project management, 25(3):290-299.

Ventä-Olkkonen L, Lanamäki, A, Iivari, N, Kuutti, K (2016). It's a Pain in the... Wild?: Struggling to Create Conditions for Emerging Practices in an Urban Computing Project. In: Proceedings of NordiCHI '16. Article No. 51.

Weber, M (1958) The Protestant Ethic and the Spirit of Capitalism. London; Boston : Unwin Hyman, 1930

Wenger, E (1998): Communities of Practice: Learning, Meaning and Identity. New York: Cambridge University Press

Winschiers-Theophilus H, Zaman T, Yeo A (2015) Reducing white elephant ICT4D projects: a community-researcher engagement. In: Proceedings of C\&T: 99-107

Ylipulli J, Luusua A, Kukka H, Ojala T (2014a) Winter is coming: Introducing climate sensitive urban computing. In: Proceedings of DIS'14:647-656

Ylipulli J, Suopajärvi T (2013) Contesting ubicomp visions through ICT practices: Power negotiation in the meshwork of a technologised city. International Communication Gazette July 11, 2013:1-17

Ylipulli J, Suopajärvi T, Ojala T, Kostakos V, Kukka H (2014b) Municipal WiFi and interactive displays: Appropriation of new technologies in public urban spaces. Technological Forecasting and Social Change, 89:145-160 